\title{
Naturally-arising amino acid polymorphisms of HIV-1 Nef that differentially modulate downregulation of HLA-A and HLA-B molecules
}

\author{
Macdonald Mahiti ${ }^{1 *}$, Philip Mwimanzi ${ }^{1,2}$, Yoko Ogata $^{1}$, Bruce Walker ${ }^{3}$, Zabrina Brumme ${ }^{2}$, Mark Brockman², \\ Takamasa Ueno'
}

From Frontiers of Retrovirology: Complex retroviruses, retroelements and their hosts Cambridge, UK. 16-18 September 2013

\section{Background}

Differential Nef-mediated down-regulation of HLA-Aand HLA-B has been reported in laboratory-adapted Nef strains [1]. Whether naturally-occurring Nef proteins exhibit differential HLA class I (HLA-I) down-regulation activities remains unknown.

\section{Materials and methods}

Plasma HIV RNA-derived Nef clones (one per patient) were isolated from 45 chronically-infected subjects and inserted into the pNL43 proviral vector. Recombinant viruses were prepared and used to infect the HLA-1deficient cell line 721.221 ectopically expressing either HLA-A $* 24$ or HLA-B*35. Following infection, cell-surface HLA-I expression of virus-infected cells was evaluated by flow cytometry using a pan HLA-I specific antibody $[2,3]$.

\section{Results}

Cell-surface HLA-I expression levels differed following infection with recombinant viruses expressing patientderived Nef, with median [IQR] expression levels of HLA-A*24 and HLA-B*35 of 38.9 [23.4-76.9] \% and 50.7 [39.9-81.9] \%, respectively, compared to those of uninfected cells as $100 \%(p<0.001)$. Thus, downregulation of HLA-A by patient-derived Nef clones was significantly more efficient than that of HLA-B, consistent with the previous observations made by laboratory-adapted strains. However, ratios of downregulation activity of HLA-A/ HLA-B were median [IQR] 1.25 [0.81-2.37], while that of control strain SF2 was 1.21 , indicating a relatively broad range of HLA-A and HLA-B downregulation activities among naturally-isolated Nef clones. Codon-function analysis of HLA-A/HLA-B downregulation ratios identified amino acid polymorphisms at position 158 and 202 as being significantly associated $(p<0.01, q<0.2)$ with relative abilities to downregulate alleles of HLA-A vs. B loci.

\section{Conclusions}

Despite a broad range of observed function, Nef-mediated ability to downregulate HLA-A exceeded that of HLA-B in $45 \mathrm{Nef}$ clones in chronic infection. We identified for the first time two Nef amino acid polymorphisms at position 158 and 202 that differentially influence HLA-A and HLA-B downregulation, suggesting that they play a role in differential interaction between Nef and allelic polymorphisms of HLA-I cytoplasmic tail.

\section{Authors' details}

${ }^{1}$ Center for AIDS Research, Kumamoto University, Kumamoto, Japan. ${ }^{2}$ Simon Fraser University, Burnaby BC, Canada. ${ }^{3}$ Ragon Institute of MGH, MIT and Harvard University, Boston, MA, USA.

\section{Published: 19 September 2013}

\section{References}

1. Rajapaksa US, Li D, Peng YC, McMichael AJ, Dong T, Xu XN: HLA-B may be more protective against HIV-1 than HLA-A because it resists negative regulatory factor (Nef) mediated down-regulation. Proc Natl Acad Sci U S A 2012, 109:13353-13358.

2. Mwimanzi $P$, Markle TJ, Martin E, Ogata Y, Kuang XT, Tokunaga M, Mahiti M, Pereyra $F$, Miura $T$, Walker $B D$, et al: Attenuation of multiple Nef functions in HIV-1 elite controllers. Retrovirology 2013, 10:1.

3. Mwimanzi P, Markle TJ, Ogata Y, Martin E, Tokunaga M, Mahiti M, Kuang XT, Walker BD, Brockman MA, Brumme ZL, et al: Dynamic range of Nef functions in chronic HIV-1 infection. Virology 2013, 439:74-80. 
doi:10.1186/1742-4690-10-S1-P54

Cite this article as: Mahiti et al: Naturally-arising amino acid polymorphisms of HIV-1 Nef that differentially modulate

downregulation of HLA-A and HLA-B molecules. Retrovirology 201310

(Suppl 1):P54.

Submit your next manuscript to BioMed Central and take full advantage of:

- Convenient online submission

- Thorough peer review

- No space constraints or color figure charges

- Immediate publication on acceptance

- Inclusion in PubMed, CAS, Scopus and Google Scholar

- Research which is freely available for redistribution

Submit your manuscript at 